\title{
Cosmetic Potential of Marine Fish Skin Collagen
}

\author{
Ana L. Alves ${ }^{1,2}$ (i), Ana L. P. Marques ${ }^{1,2}$, Eva Martins ${ }^{1,2}$ (i), Tiago H. Silva ${ }^{1,2, *}$ (1) and \\ Rui L. Reis ${ }^{1,2}$ \\ 1 3B's Research Group-Biomaterials, Biodegradables and Biomimetics, University of Minho, Headquarters of \\ the European Institute of Excellence on Tissue Engineering and Regenerative Medicine, AvePark-Parque \\ de Ciência e Tecnologia, 4805-017 Barco, Guimarães, Portugal; analves.bq@gmail.com (A.L.A.); \\ marques13@gmail.com (A.L.P.M.); eva.biotec@gmail.com (E.M.); rgreis@dep.uminho.pt (R.L.R.) \\ 2 ICVS/3B's_PT Government Associate Laboratory, Braga/Guimarães, Portugal \\ * Correspondence: tiago.silva@dep.uminho.pt; Tel.: +351-253510900; Fax: +351-253510909
}

Received: 19 September 2017; Accepted: 2 October 2017; Published: 12 October 2017

\begin{abstract}
Many cosmetic formulations have collagen as a major component because of its significant benefits as a natural humectant and moisturizer. This industry is constantly looking for innovative, sustainable, and truly efficacious products, so marine collagen based formulations are arising as promising alternatives. A solid description and characterization of this protein is fundamental to guarantee the highest quality of each batch. In the present study, we present an extensive characterization of marine-derived collagen extracted from salmon and codfish skins, targeting its inclusion as component in cosmetic formulations. Chemical and physical characterizations were performed using several techniques such as sodium dodecyl sulphate-polyacrylamide gel electrophoresis (SDS-PAGE), Fourier Transformation Infrared (FTIR) spectroscopy rheology, circular dichroism, X-ray diffraction, humidity uptake, and a biological assessment of the extracts regarding their irritant potential. The results showed an isolation of type I collagen with high purity but with some structural and chemical differences between sources. Collagen demonstrated a good capacity to retain water, thus being suitable for dermal applications as a moisturizer. A topical exposure of collagen in a human reconstructed dermis, as well as the analysis of molecular markers for irritation and inflammation, exhibited no irritant potential. Thus, the isolation of collagen from fish skins for inclusion in dermocosmetic applications may constitute a sustainable and low-cost platform for the biotechnological valorization of fish by-products.
\end{abstract}

Keywords: marine biomaterials; marine collagen; fish collagen; valorization of fish by-products moisturizer; cosmetic application

\section{Introduction}

Collagen is the major structural protein of connective tissues such as skins, tendons, ligaments, and bones, being the most prevalent component of the extracellular matrix (ECM) [1]. It represents about one-fourth of the total protein content in most animals [2,3]. It is a fibrous protein formed by three polypeptide $\alpha$ chains, arranged as a triple helix enfolded around each other. Each one is composed of a set of amino acids with a repeated motif of Gly-X-Y, where X and Y are, predominantly, proline and hydroxyproline [4]. Collagen can be extracted from several origins, with the bovine and porcine by-products being the most prevalent in an industrial context. Associated with these sources is the risk of the transference of zoonotic diseases such as BSE (bovine spongiform encephalopathy), TSE (transmissible spongiform encephalopathy), and FMD (Foot and Mouth Disease) or even religious constraints. Other sources such as marine collagen are arising as a relevant alternative to their mammalian counterparts. Several organisms such as marine sponges $[5,6]$, jellyfish $[7,8]$, squid $[9,10]$, and fishes [11-14] have been exploited for the extraction of marine collagen. About $75 \%$ of a fish's 
weight is discarded as skins, bones, fins, heads, and scales, and the scientific community has been working on a sustainable exploration of marine products and its by-products as a valorization strategy. Recent biotechnology advances have been made to discover, produce, or transform compounds from marine sources to be incorporated as functional biomaterials or bioactive compounds [15-18]. Regarding collagen, it is being used/studied in the biomedical field by the incorporation of this biopolymer in biomaterials for biomedical or pharmaceutical applications [19-22]. It can also be used for personal care, as a component in cosmetic formulations (rather in its native form or as gelatin) [23,24]. More than its contributions as an anti-aging and anti-wrinkling product [25,26], collagen has long been known and used in the development of cosmetic formulations as a moisturizer and natural humectant [27-29] component with a high substantivity to the skin [29]. Proteins of higher molecular weight, such as collagen, cannot be absorbed by the stratum corneum of the skin; they remain on the surface instead, working as water-uptake through hydration (keeping the skin moisturized) [28,30] and as protectors against microbial infiltration in cases of wounded tissue [31]. Thereby, the public search for innovative, sustainable, and efficacious products to produce new cosmetic formulations has brought marine collagen into cosmetic industry as a new, valuable, trendy component. Marine collagen-based cosmetic formulations vary in their composition and properties, species of animal, age, and catching origin. So, a good characterization practice and assessment of quality is important to choose the right collagen for each formulation.

In the present study, we use salmon and codfish skins that are rich in type I collagen to archive the moisturizing quality of marine collagen to be included as a component in cosmetic formulations. We performed an extensive physical-chemical characterization of the isolated collagen and examined both its moisture uptake capability and its irritant potential, considering the possible use of this marine collagen in cosmetic preparations.

\section{Materials and Methods}

\subsection{Materials}

Atlantic Codfish (Gadus morhua) fresh skins (non-salted) were provided by the fish processing industry (Frigoríficos da Ermida, Lda, Gafanha da Nazaré, Portugal), and Atlantic Salmon fresh skins (Salmo salar) were provided by a local supermarket. The salmon and codfish skins were transported to the laboratory facilities and stored at $-20{ }^{\circ} \mathrm{C}$ until use.

\subsection{Extraction and Purification of Collagen}

All the procedures were performed at $4{ }^{\circ} \mathrm{C}$ for the salmon and codfish species. For both species, the skins were cleaned by the removal of the remaining meat, fins, and scales. In the case of the salmon, it was also necessary to remove the excess fats: the skins were plunged in $10 \%$ ethanol for $48 \mathrm{~h}$, under stirring with medium changes twice a day. Both skins were then rinsed with distilled water and cut into small pieces to enhance collagen extraction. An acidic extraction was performed according to the method of Senaratne et al. [32], with slight modifications. To remove non-collagenous proteins, the skins were treated with $0.1 \mathrm{M} \mathrm{NaOH}(1: 10 w / v)$ for $6 \mathrm{~h}$ under stirring. The solution was changed every $2 \mathrm{~h}$, and then the skins were cleaned several times with distilled water to remove the excess $\mathrm{NaOH}$ solution, until the $\mathrm{pH}$ was close to 7 . For the extraction, the skins were plunged in $0.5 \mathrm{M}$ of acetic acid solution $(1: 10 \mathrm{w} / \mathrm{v})$ for $72 \mathrm{~h}$ under stirring, followed by centrifugation at 20,000 $\mathrm{g}$ for $1 \mathrm{~h}$ at $4{ }^{\circ} \mathrm{C}$. The supernatants, containing Acid Soluble Collagen (ASC), were collected and saved at a cold temperature $\left(4^{\circ} \mathrm{C}\right)$. In the case of the salmon, there was no need to perform a re-extraction since there were no remaining skins. However, for the codfish, the rest of the skins needed to undergo a re-extraction, following the same procedure. To precipitate the collagen, the supernatants were salted out by adding $\mathrm{NaCl}$ to a final concentration of $0.7 \mathrm{M}$, followed by precipitation by adding $\mathrm{NaCl}$ to a final concentration of $2.6 \mathrm{M}$ in $0.05 \mathrm{M}$ Tris- $\mathrm{HCl}$ ( $\mathrm{pH} 7.5)$, and left overnight. The resultant precipitates were separated by centrifugation at $20,000 \mathrm{~g}$ for $1 \mathrm{~h}$ at $4{ }^{\circ} \mathrm{C}$ and resuspended in $0.5 \mathrm{M}$ of acetic acid. 
These solutions were dialyzed against $0.1 \mathrm{M}$ acetic acid for two days; then $0.02 \mathrm{M}$ acetic acid for two days; and finally against distilled water until $\mathrm{pH}$ 7. Then, the solutions were freeze-dried and stored at room temperature until further use.

The extraction procedure was performed as previously described. The wet yield of ASC from both fish skins was calculated using Equation (1):

$$
\text { Yield of collagen }(\text { wet })(\%)=\frac{\text { Weight of collagen }(g)}{\text { Weight of wet skin }(g)} \times 100
$$

\subsection{Amino Acid Analysis}

The amino acid content of the extracted collagen was determined by quantitative amino acid analysis using a Biochrom 30 (Biochrom Ltd., Cambridge, UK) at Centro de Investigaciones Biológicas of the Spanish National Research Council (CSIC), in Madrid (Spain). The samples were first hydrolyzed and separated through a column of cation-exchange resin, following a procedure developed by Spackman, More, and Stein in 1958. The column eluent was mixed with ninhydrin reagent and eluted at a high temperature. This mixture reacted with the amino acids, forming colored compounds that were analyzed at two different wavelengths: 440 and $570 \mathrm{~nm}$. An internal standard of norleucine was used for quantitative analysis. Three independent measurements for each sample were performed for the quantification of the average amino acid contents.

\subsection{Sodium Dodecyl Sulphate-Polyacrylamide Gel Electrophoresis (SDS-PAGE)}

SDS-PAGE was prepared using reagents from Sigma SDS-PAGE reagents and casted on a Biorad Mini Protean II System. Freeze-dried collagen was mixed with 1 X Laemmli buffer at $5 \mathrm{mg} / \mathrm{mL}$ under stirring until complete dissolution. The samples were heated at $95{ }^{\circ} \mathrm{C}$ for 10 min into a digital Thermoblock TD150P3 (FALC) until the denaturation of the proteins and were centrifuged at 10,000 $g$ for $1 \mathrm{~min}$ to sediment the eventual undissolved material. For the codfish-derived collagen, $20 \mu \mathrm{L}$ of the sample was loaded to the gel, and, for the salmon collagen, $20 \mu \mathrm{L}$ and $40 \mu \mathrm{L}$ were added. Also, $4 \mu \mathrm{L}$ of protein marker was loaded along with the samples. The electrophoresis was carried out at $75 \mathrm{~V}$ for $15 \mathrm{~min}$ and then at $150 \mathrm{~V}$ until the frontline reached the lower part of the gel. After running, the gels were stained in a Coomasie (0.125\% Coomassie Blue R 250 (Biorad), 50\% Methanol, 10\% Acetic acid) staining solution for $1 \mathrm{~h}$ and then soaked in destaining solution (5\% Methanol, $7 \%$ Acetic acid) overnight.

\subsection{Fourier Transformation Infrared (FTIR) Spectroscopy}

The lyophilized samples were mixed with Sigma potassium bromide (KBr) and grinded into a powder. The compressed pellets were analyzed on a Shimadzu-IR Prestige 21 spectrometer in a spectral region of 4000 to $800 \mathrm{~cm}^{-1}$ with a resolution of $2 \mathrm{~cm}^{-1}$ using 32 individual scans in absorbance mode.

\subsection{Rheology}

Oscillatory rheological experiments were assessed on a Kinexus Pro+ rheometer (Malvern Instruments Ltd, Malvern, Worcestershire, UK) using the acquisition software rSpace. The measuring system was composed of an upper stainless steel parallel plate of a $20 \mathrm{~mm}$ diameter (PU20 SR1740SS, Malvern, UK) at a $1 \mathrm{~mm}$ gap. The oscillatory experiments were performed to obtain temperature sweep curves, after Linear Viscoelastic Region (LVER) determination, as performed by Zhang et al. [33]. The $1 \%(w / v)$ collagen solutions were heated from 20 to $40{ }^{\circ} \mathrm{C}$ at a rate of $0.5{ }^{\circ} \mathrm{C} / \mathrm{min}$. The storage modulus $\left(G^{\prime}\right)$, loss modulus $\left(G^{\prime \prime}\right)$, complex viscosity $\left(\eta^{*}\right)$, and the loss tangent $\left(\tan \delta=G^{\prime \prime} / G^{\prime}\right)$ were verified. All plots are the average of at least three experiments. 


\subsection{Circular Dichroism}

The secondary structure preservation of the collagen extracts (salmon and codfish) was evaluated through Circular Dichroism (CD). The acquisition of the spectra was performed on a Jasco Model J-1500 spectrometer (Jasco Corp., Tokyo, Japan) using a quartz cylindrical cuvette with a path length of $2 \mathrm{~mm}$. For each reading, $600 \mu \mathrm{L}$ of $0.1 \mathrm{mg} / \mathrm{mL}$ collagen solution in $50 \mathrm{mM}$ of acetic acid was placed into the cuvette. CD spectra were obtained by continuous wavelength scans (in triplicate) from 180 to $240 \mathrm{~nm}$ at a scan rate of $50 \mathrm{~nm} / \mathrm{min}$. The scans of the samples were recorded at $4{ }^{\circ} \mathrm{C}, 18^{\circ} \mathrm{C}$, and $30^{\circ} \mathrm{C}$.

\subsection{X-ray Diffraction}

The X-ray diffraction (XRD) patterns of codfish and salmon freeze-dried collagen were assessed as described by Zhang et al. [34]. The patterns were obtained by an X-ray diffractometer (Bruker D8 Discover, Karlsruhe, Germany) employing Cu-Ka radiation with a wavelength of $\lambda=1.5406 \AA$. The scan was performed in a range of $2 \theta=5^{\circ}$ to $30^{\circ}$ by a step of $0.02^{\circ}$ and a scanning speed of $2^{\circ} / \mathrm{min}$.

\subsection{Humidity Regain}

The capacity of collagen to retain water from the atmosphere was evaluated by assessing the variation of the weight upon incubation in an atmosphere with controlled humidity. Lyophilized collagen was pre-weighed and placed in a desiccator for more than $72 \mathrm{~h}$. After that, the collagen samples were transferred to a closed atmosphere system at room temperature in an environment of $32 \%$ constant relative humidity, maintained over a saturated $\mathrm{CaCl}_{2}$ solution. The same procedure was performed for a saturated atmosphere of $63 \%$ relative humidity, sustained with deionized water. The samples were incubated for $48 \mathrm{~h}$ in those conditions and then reweighed. The humidity regains were calculated and expressed as percentages of the dry weight.

\subsection{Biological Assessment}

\subsubsection{Skin Test Irritation}

The collagen potential to be an irritant to the skin was evaluated using an In Vitro Epiderm ${ }^{\mathrm{TM}}$ Assay Kit, i.e., EpiDerm (EPI-200, MatTek Corporation, Ashland, MA, USA) [35]. This 3D reconstructed human epidermal model is composed of human-derived epidermal keratinocytes and cultured on the standing cell culture inserts, forming a multilayered and highly differentiated model of the human epidermis. As recommended by the manufacturer, the tissues were preconditioned overnight at $37{ }^{\circ} \mathrm{C}$ and $5 \% \mathrm{CO}_{2}$ to overcome shipping stress. The collagen samples, positive control (PC) (Sodium Dodecyl Sulfonate, SDS, 5\% (w/v)), and negative control (NC) (sterile Dulbecco's Phosphate Buffer Saline (DPBS) ) were added to the tissues the next day and incubated for $1 \mathrm{~h}$. Subsequently, all the skin inserts were washed and transferred into fresh medium for $24 \mathrm{~h}$. The medium was recovered and stored at $-20{ }^{\circ} \mathrm{C}$ for cytokine analysis, and then the skin inserts were transferred to fresh plates for MTT (3-4,5-dimethyl thiazole 2-yl) 2,5-diphenyltetrazoliumbromide) assay. The tissues were exposed for $3 \mathrm{~h}$ at $37^{\circ} \mathrm{C}$ and $5 \% \mathrm{CO}_{2}$ to $\mathrm{MTT}$ reagent $(1 \mathrm{mg} / \mathrm{mL})$. After incubation, the tissues were washed to remove the MTT medium and then placed in fresh plates. Isopropanol was added to each insert for formazan extraction and incubated at room temperature for $2 \mathrm{~h}$ with gentle shaking on a plate shaker (120 rpm). Then the spectrophotometric analysis of the extracted formazan at $570 \mathrm{~nm}$ was carried out by transferring $200 \mu \mathrm{L}$ of extracted solution in a 96-well plate. The cytotoxicity was expressed as the ratio of the cell viability, per treatment, to the maximum cell viability from the negative control, and the collagen was then classified as either irritant or non-irritant based on the criteria in the given protocol.

\subsubsection{Cytokine Analysis}

Medium levels of IL-6 and IL-18 were measured by an enzyme-linked immunosorbent assay (ELISA) technique. The cytokine analysis was performed using commercially available ELISA kits 
(IL-6 Human Instant ELISA ${ }^{\mathrm{TM}}$ Kit and L-18 Human Instant ELISA ${ }^{\mathrm{TM}}$ Kit from eBioscience, Vienna, Austria) according to the manufacturer's instructions. The assay sensitivities for the two kits were 0.92 $\mathrm{pg} / \mathrm{mL}$ and $9.2 \mathrm{pg} / \mathrm{mL}$, respectively. The absorbance was read at $450 \mathrm{~nm}$ using a microplate reader (SYNERGY HT, BIO-TEK Instruments Inc., Winooski, VT, USA). A standard curve was generated using a five-parameter curve-fit (Microsoft Office Excel) for each set of samples assayed. The values of the samples were assigned in relation to the standard curve.

\subsection{Statistical Analysis}

All data values are presented as mean \pm Standard Deviation (SD). Statistical analysis was performed using Graph Pad Prism 5.01 software (San Diego, CA, USA) Student's t-test or One-way ANOVA followed by the post-hoc Tukey's test was used to perform the statistical analysis, and $p$-values $\leq 0.05$ were considered statistically significant $\left({ }^{* *}<0.001{ }^{* *}<0.002 ;^{*}<0.05\right)$.

\section{Results and Discussion}

\subsection{Collagen Extraction: Salmon and Codfish Skins}

Among marine sources, fish skins are widely chosen for the extraction of type I collagen. Fish skins are available at a large scale, have no risk of transmitting diseases, and have no religious constraints. Considering that $75 \%$ of a fish's weight is discarded as skins, scales, or fish bones [32], which is a result of industrial processes, it can be used as a valuable source of collagen. Codfish (Gadus morhua) and salmon (Salmo salar) skins were selected as raw materials for the isolation of type I collagen.

During ASC extraction, we observed that it was easier to solubilize collagen from salmon skin in an acidic solution than from codfish skin: for the former, there was no need for re-extraction for further solubilization of the collagen, since no skins remained after $72 \mathrm{~h}$ in the acetic acid solution.

Concerning the extraction yield of each species, for salmon skins, we obtained a yield of $19.6 \%$, while, for codfish skins, we obtained a yield of $10.9 \%$. These values correspond only to the acidic extraction and may indicate that collagen from Codfish skins is more resilient to this extraction and that it may be necessary to use further enzymatic extraction [36]. Furthermore, these values are in accordance with those observed in other studies with the same species or others [36,37].

\subsection{Chemical and Physical Characterization of the Extracted Collagen}

\subsubsection{Amino acid Content of Collagen Extracts}

There are some characteristics that make collagen unique. The amino acid analysis allows us to understand the quantitative composition of collagen. Hydroxyproline (OHPro), for example, is an amino acid present in collagen in a barely exclusive way, playing a key role on its stability. It accounts for about $13 \%$ of collagen's weight, being almost non-existent in other proteins. Another one that is revealed to be in large quantities in collagen is Glycine (Gly); in every sequence of three amino acids on each chain of the collagen triple helix, one of them is glycine (Gly-X-Y). The other two positions are commonly for Proline (Pro, in position X or Y) and Hydroxyproline (OHPro, in position Y) [38].

Table 1 shows the amino acid composition for codfish and salmon based collagen. These results are very similar to those found by other researchers for the same species [39]. Slight differences can be observed, but, as mentioned before, it is possible to validate the higher presence of glycine in both, comprising up to $1 / 3$ of the total residues, as well as alanine, as was expected [40].

The content of proline and hydroxyproline in collagen was 121/1000 for salmon and 146/1000 for codfish, which was similar to those reported by and Tylingo et al. [41] and Duan et al. [42], respectively, with a hydroxylation degree of about $40 \%$ in both cases. It is known that the presence of high hydroxyproline residues is related to higher denaturation temperatures [43] and an increase of the stability of the triple helix of collagen due to the hydrogen bonds between the polypeptides [44]. We observed a higher content of hydroxyproline in codfish them in salmon. It is also expected 
that marine origin collagen has a lower hydroxyproline content, compared to its mammalian counterparts [34,42,45], which is probably due to the marine environment that these two species are from. Both are cold-water fishes, and that is reflected in their lower hydroxyproline content when compared with other species from warmer waters $[39,45]$.

Table 1. Amino acid content of collagen extracts obtained from salmon and codfish skins.

\begin{tabular}{ccc}
\hline \multirow{2}{*}{ Amino Acid } & Salmon Collagen & Codfish Collagen \\
\cline { 2 - 3 } & \multicolumn{3}{c}{ moL \% } \\
Asp & 47 & 51 \\
Thr & 16 & 23 \\
Ser & 56 & 67 \\
Glu & 71 & 71 \\
Gly & 365 & 332 \\
Ala & 121 & 106 \\
Cys & 3 & 5 \\
Val & 18 & 19 \\
Met & 28 & 17 \\
Ile & 6 & 11 \\
Leu & 24 & 21 \\
Nleu & 27 & 22 \\
Tyr & 1 & 4 \\
Phe & 16 & 12 \\
OHLys & 12 & 7 \\
His & 9 & 8 \\
Lys & 25 & 26 \\
Arg & 36 & 51 \\
OHPro & $\mathbf{4 8}$ & $\mathbf{5 5}$ \\
Pro & 1000 & $\mathbf{9 1}$ \\
Total & & 1000 \\
\hline
\end{tabular}

\subsubsection{SDS-PAGE Analysis}

The SDS-PAGE technique separates macromolecules such as nucleic acids and protein fragments according to their molecular weight or size, based on differences in electrophoretic mobility under an applied electrical field. Thus, this technique accesses the structural information, purity, and breakdowns in collagen proteins.

In Figure 1, the SDS-PAGE patterns for both the salmon and codfish skin extracts show the characteristic bands of collagen, namely the $\alpha$ and $\beta$ chains.

For both species, salmon (a) and codfish (b) electrophoresis analysis demonstrated the presence of $\alpha_{1}$ and $\alpha_{2}$ chains, correspondent to type I collagen [1,46], as well the presence of $\beta$ dimer. The $\beta$ component indicates that both collagens contain inter-molecular crosslinks. Similar patterns were found for salmon and codfish by others $[40,41,47]$, as well as for other types of fishes such as Japanese sea-bass, bullhead shark, and chub mackerel [48]; brown backed toadfish [32]; Deep-sea Redfish [49]; European carp [42]; striped catfish [50]; and Indian carp and Mrigal carp [51]. Also, a $\gamma$ trimer can be also spotted in codfish, indicating that intra-molecular crosslinking is also present in the three chains of collagen. This demonstrates the possibility of renaturing the native collagen [52]. A slightly shift in the position of the $\alpha$ and $\beta$ chains can be observed between the species. This may be probably due to differences in the amino acid composition that lead to slight alterations in the molecular weight [37]. 


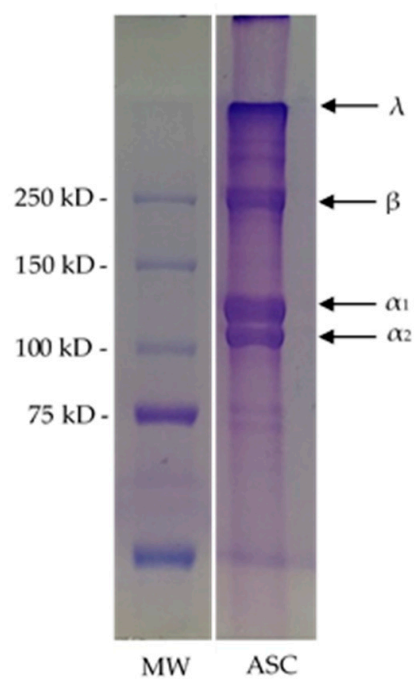

(a)

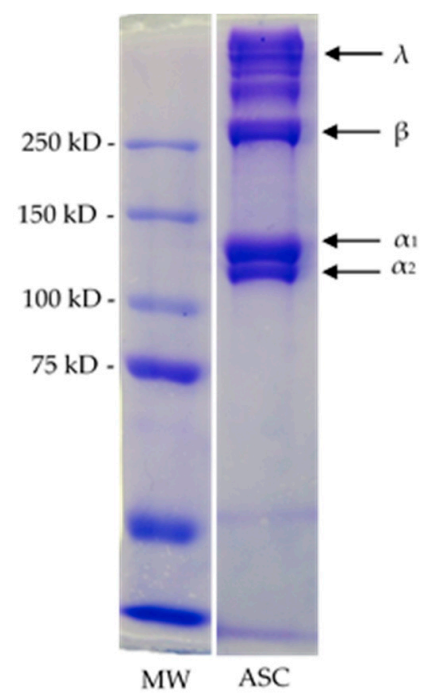

(b)

Figure 1. Electrophoresis analysis of salmon and codfish skin collagen. (a) Sodium Dodecyl Sulphate-Polyacrylamide Gel Electrophoresis (SDS-PAGE) pattern of salmon collagen by Acid Soluble Collagen (ASC) extraction; (b) SDS-PAGE pattern of Codfish collagen by ASC extraction.

\subsubsection{FTIR Analysis}

The extracted material from both marine sources was analysed through Fourier Transform InfraRed spectroscopy (FTIR) to identify collagen by the presence of characteristic bands. Figure 2 showed the spectra for the ASC of salmon and codfish collagen. The overall spectra profile suggests that the collagens extracted from salmon and codfish are comparable, indicating that both have similar structural and chemical compositions, with visible the reference peaks for collagen being characteristic of amide A, amide B, amide I, amide II, and amide III. The amide A band is relative to the N-H stretching vibration typical of intermolecular hydrogen bonding and is commonly observed in a range between 3000 and $3500 \mathrm{~cm}^{-1}$.

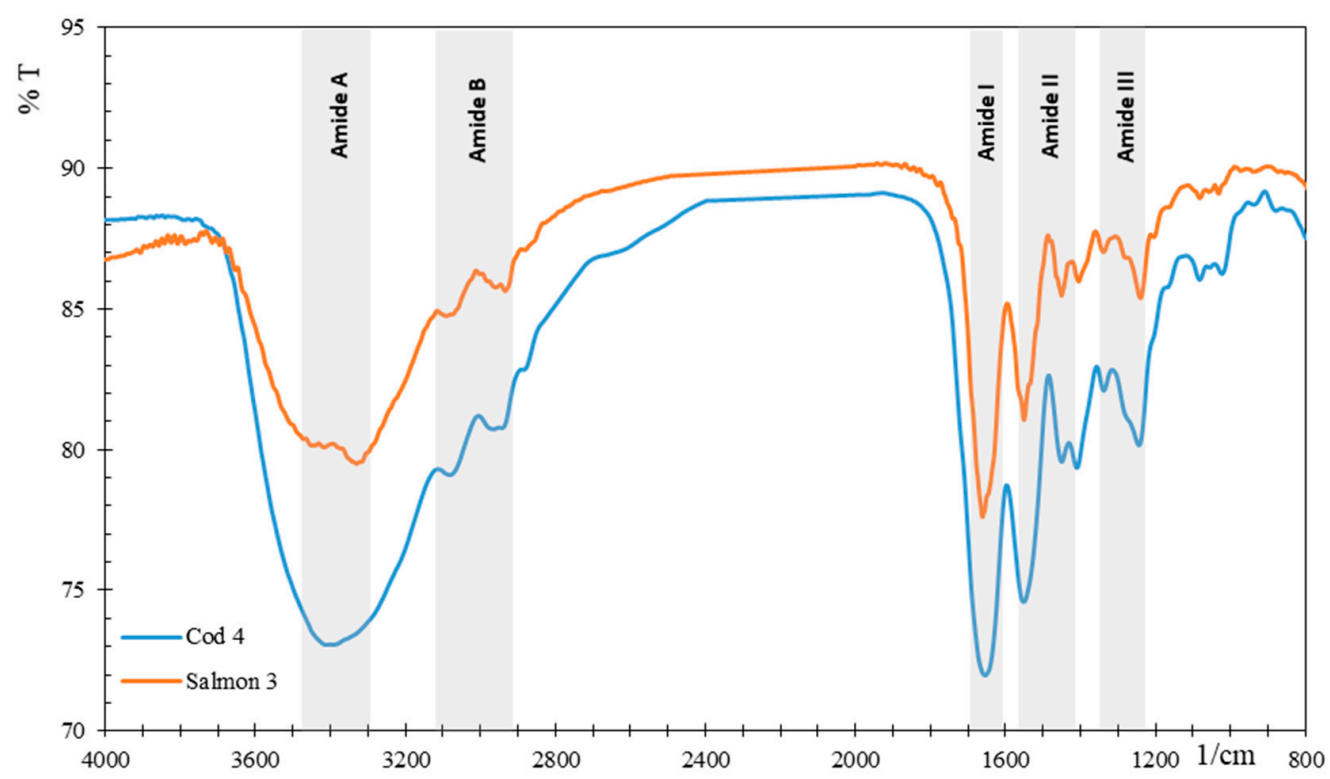

Figure 2. Fourier Transform InfraRed spectroscopy (FTIR) spectra of the ASC of salmon (red line) and codfish (blue line) collagen. 
The FTIR profile can be observed proximally at $3473 \mathrm{~cm}^{-1}$ for salmon and $3410 \mathrm{~cm}^{-1}$ for codfish. Also for salmon and codfish, amide B, relative to the asymmetrical and symmetrical stretch of $\mathrm{CH}_{2}$, is found at $3074 \mathrm{~cm}^{-1}$ and $2941 \mathrm{~cm}^{-1}$, respectively. The amide I peak, characteristic of the stretching vibrations of $C=O$ groups of proteins arises at $1660 \mathrm{~cm}^{-1}$ and $1653 \mathrm{~cm}^{-1}$. For salmon and codfish, the absorption band characteristic of amide II was very similar. The peaks arise at $1550 \mathrm{~cm}^{-1} / 1548 \mathrm{~cm}^{-1}$, correspondent to the $\mathrm{NH}$ bending vibration coupled with $\mathrm{CN}$ stretching; $1450 \mathrm{~cm}^{-1}$, attributed to $\mathrm{CH}_{2}$ bending; and $1404 \mathrm{~cm}^{-1} / 1409 \mathrm{~cm}^{-1}$, derived from COO-symmetrical stretching, respectively. Additionally, bands of amide III are also present at $1338 \mathrm{~cm}^{-1} / 1336 \mathrm{~cm}^{-1}$, correspondent to the NH bending associated with $\mathrm{CN}$ stretching, and at $1240 \mathrm{~cm}^{-1} / 1244 \mathrm{~cm}^{-1}$, relative to $\mathrm{C}-\mathrm{O}$ stretching, respectively. The absorption ratio between the amide III and $1450 \mathrm{~cm}^{-1}$ peaks was near to 1 (1.01 for salmon and 0.97 for codfish), which was an indicator of the preservation of the triple helix structure of collagen [49,53-56]. These findings are similar to other findings found in the literature for other marine species [42,57-59], as well as the ones in this study [41].

\subsubsection{Rheology}

Changes in the temperature range affect the rheological properties of collagen in solution, which can be translated as alterations in its structure. From LVER determination, at $1 \mathrm{~Hz}$ of frequency, a shear strain of $5 \%$ was defined to be used on the oscillatory experiments. In Figure 3, the effect of temperature on the structure of collagen was assessed by measuring the complex viscosity $\left(\eta^{*}\right)$ and the loss angle (tan $\delta)$ through a range of temperatures $\left(20\right.$ to $\left.40{ }^{\circ} \mathrm{C}\right)$. The decrease of $\eta^{*}$ and a concomitant rapid increase in $\tan \delta$ reflect the fragility and further collapse of collagen's triple helix into a random coil [33]. The temperature at which these events occur is considered by some authors as the denaturation temperature under dynamic rheological measurement $[33,60]$. However, from our point of view, this event is characterized as the gelation point at which disorganized chains reorganize to form a gel. That point is determined as the temperature at which the decrease of $\eta^{*}$ reached $50 \%$ of its initial value or as the temperature at which the increase of $\tan \delta$ achieved a peak value.
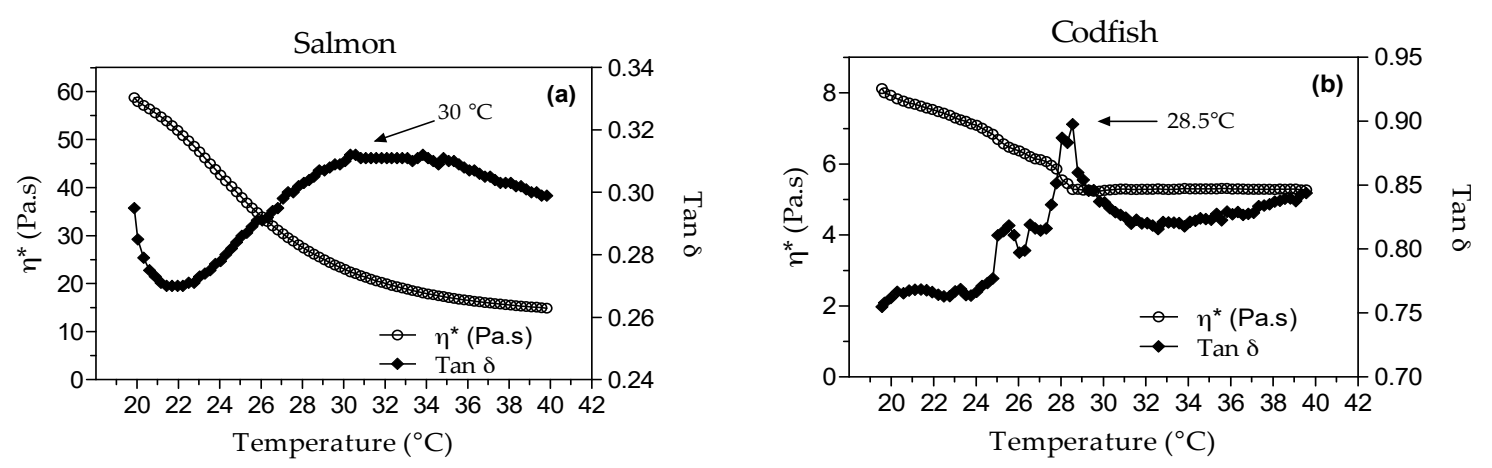

Figure 3. Temperature dependence of $\eta^{*}$ and $\tan \delta$ for $1.0 \%$ of the ASC of (a) salmon and (b) codfish collagen.

For salmon collagen, that value is approximately $30{ }^{\circ} \mathrm{C}$, and, for codfish collagen, it is about $28.5^{\circ} \mathrm{C}$. These values are slightly lower when compared, for example, with collagen from largefin longbarbel catfish but are justified by taking into account the cold-water origin of the former fishes. The different behaviors of these rheological patterns may be due to the difference in the viscosity of collagen in $0.02 \mathrm{M}$ acetic acid, in which salmon collagen kept a more gelified appearance than codfish collagen.

\subsubsection{Circular Dichroism}

CD spectroscopy is typically used to assess the protein secondary structure through the differential absorption of left and right handed circular polarized light in an asymmetric environment [61,62]. 
In Figure 4, the results of the CD spectroscopy analysis of salmon and codfish collagen can be observed, with clear differences between both marine species (Figure 4a). Regarding salmon collagen, a positive band was observed at $222 \mathrm{~nm}$, which is characteristic of triple helix, and a pronounced negative band around 196 to $200 \mathrm{~nm}$, typical of a random coil structure [63], while, for codfish, no positive band was observed at $220 \mathrm{~nm}$, indicating that the triple helix is preserved only in salmon collagen To evaluate the effect of temperature on the triple helix structure, a range of temperatures were settled. At $4{ }^{\circ} \mathrm{C}$ (Figure 4a), it is possible to observe the triple helical structure by the presence of a positive peak that decreases with the increase of temperature from 4 to $18^{\circ} \mathrm{C}$ and $30^{\circ} \mathrm{C}$ (Figure $4 \mathrm{~b}, \mathrm{c}$ ). At the maximum temperature, the native collagen structure was completely destroyed.

Through a statistical analysis using a Nonlinear Curve Fit (Boltzmann function), which produces a sigmoidal curve, the denaturation temperatures of both collagen extracts were calculated. For salmon collagen, the denaturation temperature was around $27^{\circ} \mathrm{C}$. However, in the case of codfish, it was not possible to determine.

\section{$4^{\circ} \mathrm{C}$}

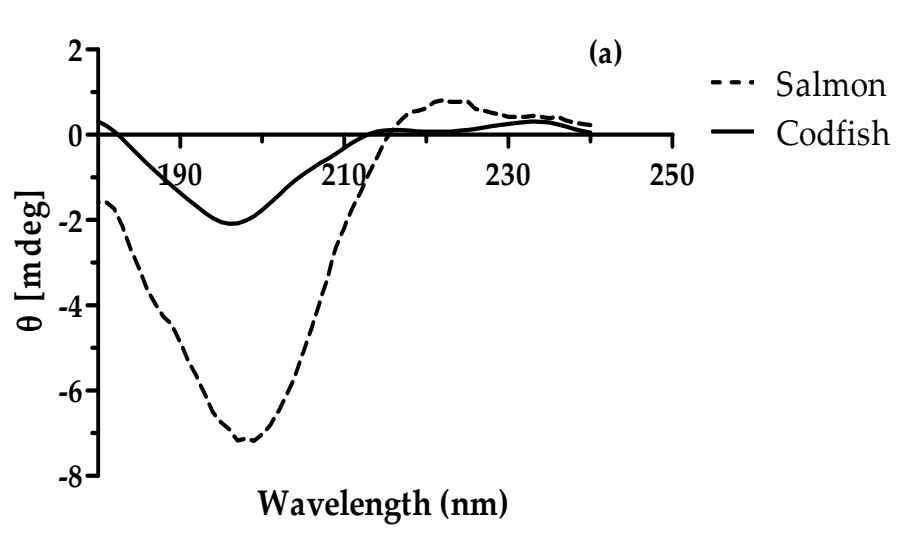

$18^{\circ} \mathrm{C}$

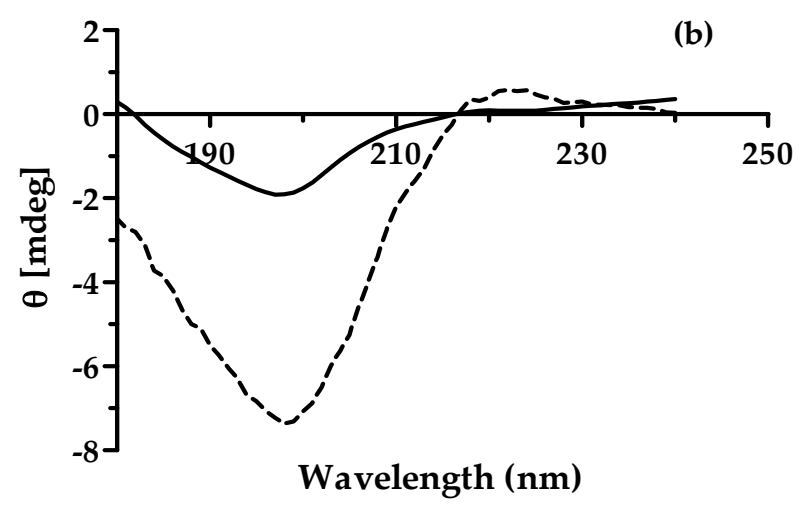

Figure 4. Cont. 


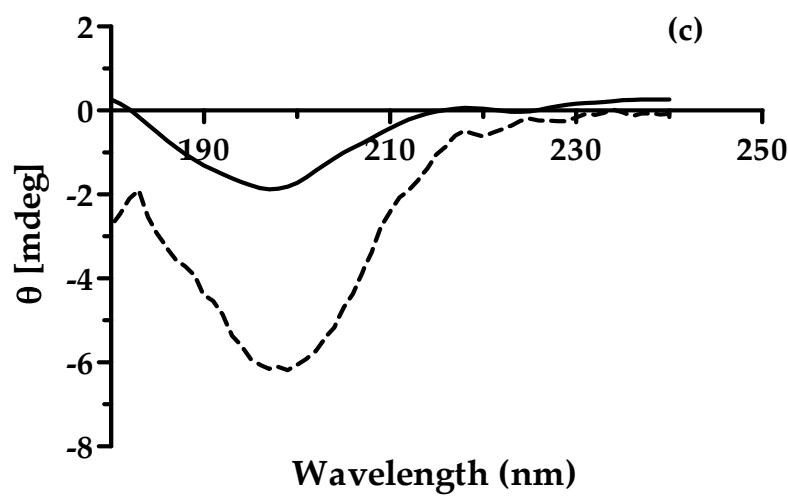

Figure 4. CD spectra of ASC collagen from Salmon and Codfish in different range temperature (a) $4{ }^{\circ} \mathrm{C}$; (b) $18^{\circ} \mathrm{C}$; and (c) $30^{\circ} \mathrm{C}$.

\subsubsection{X-ray Diffraction}

$\mathrm{X}$-ray diffraction is often used to assess collagen fibril distribution and orientation in fish mineralized tissues [34,64]. Figure 5 illustrates the X-ray spectra of lyophilized acid-soluble collagen from Salmon (a) and Codfish (b) skins. The difference in organization between the structures of Salmon and Codfish collagen were visible, with Salmon collagen spectrum presenting two peaks well featured but, on the other hand, Codfish spectrum showed a flattened pattern. These two peaks are characteristic of collagen molecule and can be seen as a signature. The first one and sharpest is related to the triple helix conformation and distance between molecular chains, and the second peak is related to the distance between the skeletons. The diffraction angles $(2 \theta)$ of Salmon were about $7.70^{\circ}$ and $19.59^{\circ}$ and using Bragg equation $d(\AA)=\lambda / 2 \sin \theta(\lambda=1.54 \AA)$ [34], the minimum values (d) of the repeated spacings were calculated. The $\mathrm{d}$ corresponding to the sharp peak was $11.46 \AA$ and for the wide peak was $4.52 \AA$. These values are closed to those reported by Zhang et al. [34] corroborating that our Salmon collagen has triple helix structure preserved, which is not detected on Codfish collagen.

Salmon

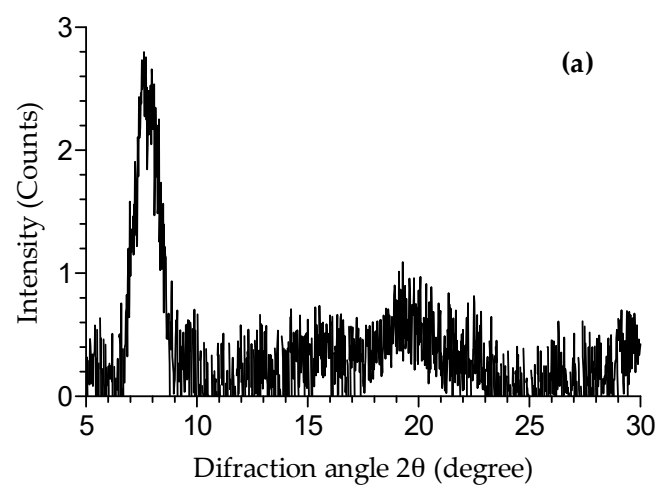

Codfish

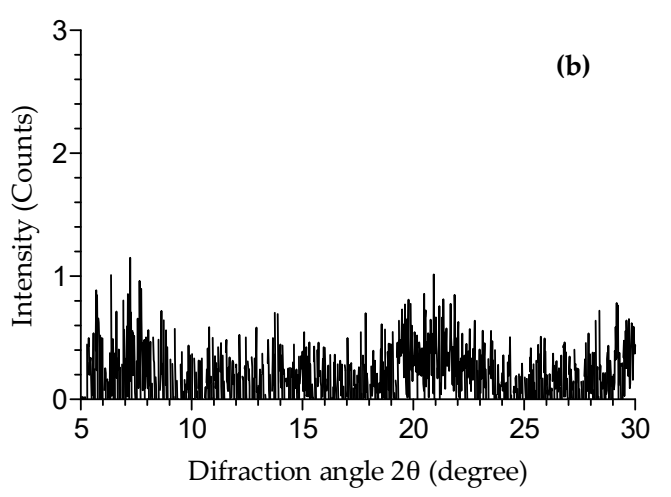

Figure 5. X-ray spectra of ASC collagen from (a) salmon and (b) codfish skins.

\subsection{Humidity Regain Analysis}

The ability for collagen to retain water is fundamental to its successful performance as cosmetic component, with its main role being involved in on the control of skin moisture. Its capacity to be a natural humectant was evaluated by measuring the relative water uptake from the atmosphere, using freeze-dried samples under constant atmospheric humidity. From a perspective of biotechnological 
valorization of fish by-products, the codfish is a more interesting species in the Portuguese context. The industry exploration of this fish is very pronounced in our country, and the need for the valorization of derived by-products is important for a sustainable exploitation of this resource, with environmental and economic advantages. Therefore, we choose to use the codfish derived collagen for the next experiments; the fact that codfish collagen did not show a preserved triple helical structure is not relevant for cosmetic applications.

First, we exposed the dried samples to a relative humidity of $30 \%$, using a saturated solution of $\mathrm{CaCl}_{2}$ to maintain it constantly. After $24 \mathrm{~h}$, a slight increase in weight can be seen (Figure 6) due to the water uptake, which is not very pronounced, mainly because of the lower water availability in the environment. After $48 \mathrm{~h}$ of exposure, the codfish collagen did not present expressive differences in weight because the system reached the equilibrium stage.

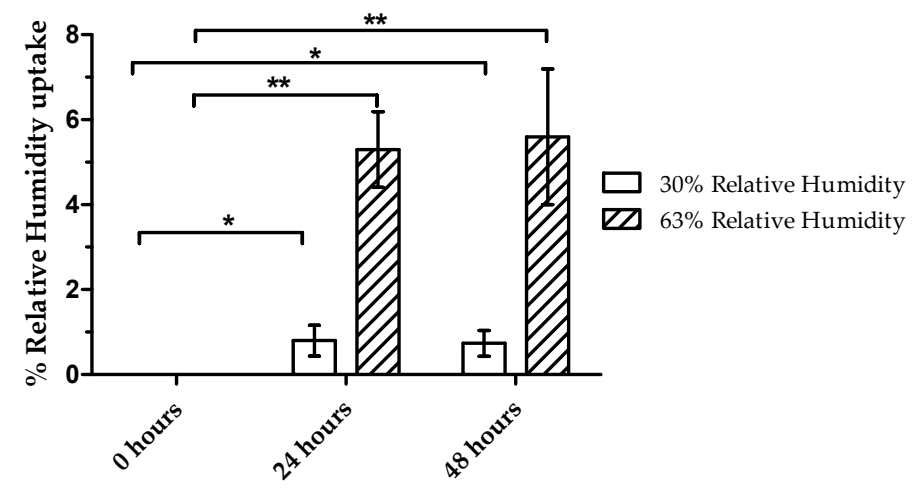

Figure 6. Measurement of the water uptake of codfish collagen under different percentages of relative humidity. Values are Mean \pm SD of at least three individual measurements. ${ }^{*} p<0.05$ and ${ }^{* *} p<0.002$ when the time was compared by one-way ANOVA, followed by Tukey's test.

When the samples were exposed to $63 \%$ relative humidity, the water uptake increased significantly, by about $6 \%$ of the sample's weight. This result is in accordance with other measurements performed on commercial collagens suitable for cosmetic applications [29]. Also, an experiment with a fully saturated atmosphere (98\% relative humidity) was performed (data not shown), and the sample absorbed a considerable quantity of water, forming wet slurries. For both conditions, the water uptake was kept constant after $24 \mathrm{~h}$, an important indicator that collagen could be able to retain water, keeping a moisturized skin.

\subsection{Evaluation of Skin Irritation Potential}

\subsubsection{Effect over Viability of Keratinocytes on Reconstructed Skin Model}

Assessing the irritant potential of a cosmetic component is of great importance when preparing a formulation to apply to the skin. Although the induced irritation can be reversible in some cases, there are others in which it can evolve into permanent damage. Reconstructed models of human epidermis have been used to mimic human skin and then assess the tolerance of human skin to potential irritants in cosmetic formulations $[65,66]$. In Figure 7 , we can observe that the viability of keratinocytes was not significantly affected by the presence of codfish collagen.

The skin irritation potential of collagen is predicted if the mean relative tissue viability of three individual tissues is bellow to $50 \%$, when compared with the negative control (NC) [67], as clearly observed in the presence of 5\% SDS (PC). The codfish collagen shows a relative cell viability superior to $50 \%$ and it is, thus, considered a non-irritant. 


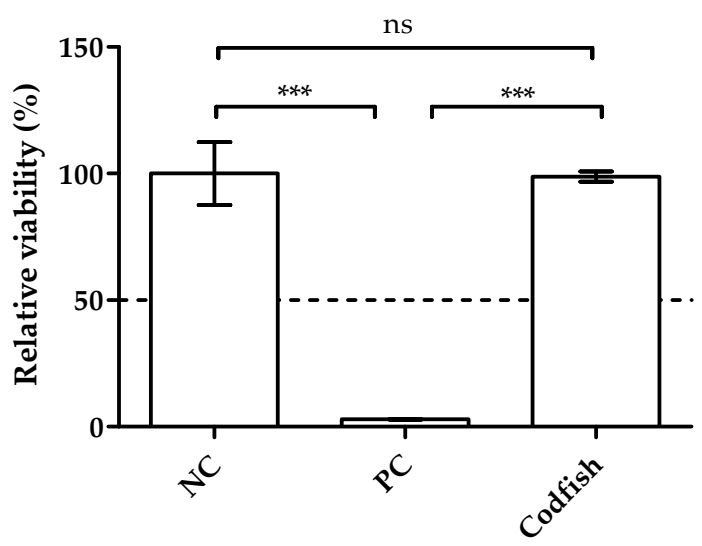

Figure 7. MTT cytotoxicity assay of codfish collagen to assess skin irritation. Values are Mean \pm SD of at least three individual tissues. ${ }^{* * *} p<0.0001$, when compared with positive control (PC) by one-way ANOVA, followed by Tukey's test.

\subsubsection{Cytokine Analysis}

The irritant and inflammatory potentials of codfish collagen were also evaluated by measuring the expression levels of two key cytokines, IL-18 and IL-6. Interleukin (IL)-18 is a member of the IL-1 family of cytokines, which are expressed by many cells, including keratinocytes [68]. It is a marker for irritability and is highly expressed in some skin diseases such as psoriasis, atopic dermatitis, urticaria, contact dermatitis, and drug allergy [69]. Interleukin (IL)-6 is believed to be the central regulator of the immunological processes and a well-known marker of inflammatory states [70].

The results for cytokine assays are derived from the same tissues that generate the relative viability data, as well as the controls. For both IL-18 and IL-6, no evidence of the release of those cytokines was detected for the time period of incubation with the collagen $(1 \mathrm{~h})$. Overall, this data supports the idea that the tested codfish collagen can be considered a non-irritant, being safe for dermocosmetic formulations.

\section{Conclusions}

To input value to by-products of marine species in a sustainable way, salmon and codfish skins were used for collagen extraction. Collagen with high purity was extracted, as can be observed by SDS-PAGE and FTIR, with the former displaying profiles compatible with type I collagen. The effect of temperature on collagen stability was evaluated by rheology, which showed a gelation temperature of $30{ }^{\circ} \mathrm{C}$ for salmon and $28.5{ }^{\circ} \mathrm{C}$ for codfish. Moreover, $\mathrm{CD}$ analysis revealed the presence of a triple helix structure in salmon collagen, with a denaturation temperature of around $27^{\circ} \mathrm{C}$, while, in codfish collagen, no triple helix was detected. Considering a biotechnological valorization of the produced collagens, the cosmetic evaluation was processed using codfish collagen, which showed a good moisturizing effect through water absorption, preventing skin dehydration without signs of irritancy to the skin, as demonstrated by topical exposure and cytokine evaluation.

This study demonstrated that the common sources of collagen in cosmetic applications can be substituted with marine collagen as a sustainable platform for the biotechnological valorization of fish by-products.

Acknowledgments: The authors would like to acknowledge to European Union for the financial support under the scope of European Regional Development Fund (ERDF) through the projects 0687_NOVOMAR_1_P (POCTEP (Programa Operacional de Cooperação Transfronteiriça España-Portugal) 2007/2013) and 0302_CVMAR_I_1_P (POCTEP 2014/2020) and the Structured Project NORTE-01-0145-FEDER-000021 (Norte2020) and under the scope of the European Union Seventh Framework Programme (FP7/2007-2013) through grant agreement ERC-2012-ADG 20120216-321266 (ERC Advanced Grant ComplexiTE). The Portuguese Foundation for Science and Technology is also acknowledged for the grant of A.L.A (Ana Luísa Alves.) under Doctoral Programme Do* Mar (PD/BD/127995/2016). The authors also thank Sandra Pina (3B's Research Group) for her assistance with 
the XRD measurements, Cristiana Gonçalves (3B's Research Group) for helping with the rheology results analysis, and Cristina Thiebaut (Cobiosa Industrias Asociadas SL, Spain) for her discussion on the cosmetic relevance of collagen. Frigoríficos da Ermida, Lda. and Pingo Doce Braga are also gratefully acknowledged for their offers of codfish and salmon skins, respectively.

Author Contributions: Tiago H. Silva and Rui L. Reis conceived the study; Ana L. Alves, Ana L. P. Marques, Eva Martins and Tiago H. Silva designed the experiments; Ana L. Alves, Ana L. P. Marques and Eva Martins performed the experiments; Ana L. Alves, Eva Martins and Tiago H. Silva analyzed the data; Rui L. Reis contributed reagents/materials/analysis tools; Ana L. Alves and Eva Martins wrote the manuscript; Tiago H. Silva and Rui L. Reis revise the paper.

Conflicts of Interest: The authors declare no conflicts of interest.

\section{References}

1. Shoulders, M.D.; Raines, R.T. Collagen structure and stability. Annu. Rev. Biochem. 2009, 78, 929-958. [CrossRef] [PubMed]

2. Bailey, A. The nature of collagen. Compr. Biochem. 1968, 26, 297-423.

3. Prockop, D.J.; Kivirikko, K.I. Collagens: Molecular biology, diseases, and potentials for therapy. Annu. Rev. Biochem. 1995, 64, 403-434. [CrossRef] [PubMed]

4. Ramshaw, J.A.; Shah, N.K.; Brodsky, B. Gly-xy tripeptide frequencies in collagen: A context for host-guest triple-helical peptides. J. Struct. Biol. 1998, 122, 86-91. [CrossRef] [PubMed]

5. Silva, J.C.; Barros, A.A.; Aroso, I.M.; Fassini, D.; Silva, T.H.; Reis, R.L.; Duarte, A.R.C. Extraction of collagen/gelatin from the marine demosponge chondrosia reniformis (nardo, 1847) using water acidified with carbon dioxide-process optimization. Ind. Eng. Chem. Res. 2016, 55, 6922-6930. [CrossRef]

6. Tziveleka, L.-A.; Ioannou, E.; Tsiourvas, D.; Berillis, P.; Foufa, E.; Roussis, V. Collagen from the marine sponges axinella cannabina and suberites carnosus: Isolation and morphological, biochemical, and biophysical characterization. Mar. Drugs 2017, 15, 152. [CrossRef] [PubMed]

7. Jankangram, W.; Chooluck, S.; Pomthong, B. Comparison of the properties of collagen extracted from dried jellyfish and dried squid. Afr. J. Biotechnol. 2016, 15, 642-648.

8. Cheng, X.; Shao, Z.; Li, C.; Yu, L.; Raja, M.A.; Liu, C. Isolation, characterization and evaluation of collagen from jellyfish rhopilema esculentum kishinouye for use in hemostatic applications. PLoS ONE 2017, 12, e0169731. [CrossRef] [PubMed]

9. Cozza, N.; Bonani, W.; Motta, A.; Migliaresi, C. Evaluation of alternative sources of collagen fractions from loligo vulgaris squid mantle. Int. J. Biol. Macromol. 2016, 87, 504-513. [CrossRef] [PubMed]

10. Coelho, R.C.; Marques, A.L.; Oliveira, S.M.; Diogo, G.S.; Pirraco, R.P.; Moreira-Silva, J.; Xavier, J.C.; Reis, R.L.; Silva, T.H.; Mano, J.F. Extraction and characterization of collagen from antarctic and sub-antarctic squid and its potential application in hybrid scaffolds for tissue engineering. Mater. Sci. Eng. C 2017, 78, 787-795. [CrossRef] [PubMed]

11. Huang, C.-Y.; Kuo, J.-M.; Wu, S.-J.; Tsai, H.-T. Isolation and characterization of fish scale collagen from tilapia (oreochromis sp.) by a novel extrusion-hydro-extraction process. Food Chem. 2016, 190, 997-1006. [CrossRef] [PubMed]

12. Chen, S.; Chen, H.; Xie, Q.; Hong, B.; Chen, J.; Hua, F.; Bai, K.; He, J.; Yi, R.; Wu, H. Rapid isolation of high purity pepsin-soluble type i collagen from scales of red drum fish (Sciaenops ocellatus). Food Hydrocoll. 2016, 52, 468-477. [CrossRef]

13. Silvipriya, K.; Kumar, K.K.; Kumar, B.D.; John, A.; Lakshmanan, P. Fish processing waste: A promising source of type-i collagen. Curr. Trends Biotechnol. Pharm. 2016, 10, 374-383.

14. Iswariya, S.; Velswamy, P.; Uma, T. Isolation and characterization of biocompatible collagen from the skin of puffer fish (Lagocephalus inermis). J. Polym. Environ. 2017, 1-10. [CrossRef]

15. Silva, T.H.; Alves, A.; Ferreira, B.; Oliveira, J.M.; Reys, L.; Ferreira, R.; Sousa, R.; Silva, S.; Mano, J.; Reis, R. Materials of marine origin: A review on polymers and ceramics of biomedical interest. Int. Mater. Rev. 2012, 57, 276-306. [CrossRef]

16. Kim, S.-K. Marine Proteins and Peptides: Biological Activities and Applications; John Wiley \& Sons: Hoboken, NJ, USA, 2013.

17. Cheung, R.C.F.; Ng, T.B.; Wong, J.H. Marine peptides: Bioactivities and applications. Mar. Drugs 2015, 13, 4006-4043. [CrossRef] [PubMed] 
18. Mao, X.; Liu, Z.; Sun, J.; Lee, S.Y. Metabolic engineering for the microbial production of marine bioactive compounds. Biotechnol. Adv. 2017. [CrossRef] [PubMed]

19. Silvipriya, K.; Kumar, K.K.; Bhat, A.; Kumar, B.D.; John, A. Collagen: Animal Sources and Biomedical Application. J. Appl. Pharm. Sci. 2015, 5, 123-127. [CrossRef]

20. Hadzik, J.; Kubasiewicz-Ross, P.; Kunert-Keil, C.; Jurczyszyn, K.; Nawrot-Hadzik, I.; Dominiak, M.; Gedrange, T. A silver carp skin derived collagen in bone defect treatment-A histological study in a rat model. Ann. Anat. 2016, 208, 123-128. [CrossRef] [PubMed]

21. Moreira-Silva, J.; Diogo, G.S.; Marques, A.L.; Silva, T.H.; Reis, R.L. Marine collagen isolation and processing envisaging biomedical applications. Biomater. Nat. Adv. Devices Ther. 2016, 16. [CrossRef]

22. Hu, Z.; Yang, P.; Zhou, C.; Li, S.; Hong, P. Marine collagen peptides from the skin of nile tilapia (oreochromis niloticus): Characterization and wound healing evaluation. Mar. Drugs 2017, 15, 102. [CrossRef] [PubMed]

23. Guillerme, J.-B.; Couteau, C.; Coiffard, L. Applications for marine resources in cosmetics. Cosmetics 2017, 4, 35. [CrossRef]

24. Siahaan, E.A.; Pangestuti, R.; Munandar, H.; Kim, S.-K. Cosmeceuticals properties of sea cucumbers: Prospects and trends. Cosmetics 2017, 4, 26. [CrossRef]

25. Xhauflaire-Uhoda, E.; Fontaine, K.; Pierard, G. Kinetics of moisturizing and firming effects of cosmetic formulations. Int. J. Cosmet. Sci. 2008, 30, 131-138. [CrossRef] [PubMed]

26. Hayashi, Y.; Yamada, S.; Ikeda, T.; Yanagiguchi, K. 11 fish collagen and tissue repair. In Marine Cosmeceuticals: Trends and Prospects; CRC Press: Boca Raton, FL, USA, 2011.

27. Morgantii, P.; Randazz, S.; Cardillo, A. Role of insoluhle and soluhle collagen as skin moisturizer. J. Appl. Cosmetol. 1986, 4, 141-152.

28. Elsner, P.; Berardesca, E.; Maibach, H.I. Bioengineering of the Skin: Water and the Stratum Corneum; CRC Press: Boca Raton, FL, USA, 1994; Volume 1.

29. Peng, Y.; Glattauer, V.; Werkmeister, J.A.; Ramshaw, J.A. Evaluation for collagen products for cosmetic application. Int. J. Cosmet. Sci. 2004, 26, 313. [CrossRef]

30. Swatschek, D.; Schatton, W.; Kellermann, J.; Müller, W.E.; Kreuter, J. Marine sponge collagen: Isolation, characterization and effects on the skin parameters surface-ph, moisture and sebum. Eur. J. Pharm. Biopharm. 2002, 53, 107-113. [CrossRef]

31. Kim, S.-K.; Ngo, D.-H.; Vo, T.-S.; Ryu, B. Industry perspectives of marine-derived proteins as biomaterials. In Marine Biomaterials; CRC Press: Boca Raton, FL, USA, 2013; pp. 737-746.

32. Senaratne, L.; Park, P.-J.; Kim, S.-K. Isolation and characterization of collagen from brown backed toadfish (lagocephalus gloveri) skin. Bioresour. Technol. 2006, 97, 191-197. [CrossRef] [PubMed]

33. Zhang, M.; Chen, Y.; Li, G.; Du, Z. Rheological properties of fish skin collagen solution: Effects of temperature and concentration. Korea-Aust. Rheol. J. 2010, 22, 119-127.

34. Zhang, F.; Wang, A.; Li, Z.; He, S.; Shao, L. Preparation and characterisation of collagen from freshwater fish scales. Food Nutr. Sci. 2011, 2, 818-823. [CrossRef]

35. Kandárová, H.; Hayden, P.; Klausner, M.; Kubilus, J.; Sheasgreen, J. An in vitro skin irritation test (sit) using the epiderm reconstructed human epidermal (rhe) model. J. Vis. Exp. 2009, 1366. [CrossRef]

36. Venkatesan, J.; Anil, S.; Kim, S.-K.; Shim, M.S. Marine fish proteins and peptides for cosmeceuticals: A review. Mar. Drugs 2017, 15, 143. [CrossRef] [PubMed]

37. Silva, T.H.; Moreira-Silva, J.; Marques, A.L.; Domingues, A.; Bayon, Y.; Reis, R.L. Marine origin collagens and its potential applications. Mar. Drugs 2014, 12, 5881-5901. [CrossRef] [PubMed]

38. Soottawat Benjakul, S.N. Fereidoon Shahidi. Fish collagen. In Food Biochemistry and food Processing; Simpson, B.K., Ed.; John Wiley \& Sons, Inc.: Hoboken, NJ, USA, 2012; pp. 365-387.

39. Regenstein, J.; Zhou, P. Collagen and gelatin from marine by-products. In Maximising the Value of Marine by-Products; Woodhead Publishing: Cambridge, UK, 2007; pp. 279-303.

40. Gómez-Guillén, M.C.; Turnay, J.; Fernández-Diaz, M.D.; Ulmo, N.; Lizarbe, M.A.; Montero, P. Structural and physical properties of gelatin extracted from different marine species: A comparative study. Food Hydrocoll. 2002, 16, 25-34. [CrossRef]

41. Tylingo, R.; Mania, S.; Panek, A.; Piątek, R.; Pawłowicz, R. Isolation and characterization of acid soluble collagen from the skin of african catfish (Clarias gariepinus), salmon (Salmo salar) and baltic cod (Gadus morhua). J. Biotechnol. Biomater. 2016, 6, 2. [CrossRef] 
42. Duan, R.; Zhang, J.; Du, X.; Yao, X.; Konno, K. Properties of collagen from skin, scale and bone of carp (Cyprinus carpio). Food Chem. 2009, 112, 702-706. [CrossRef]

43. Rosenbloom, J.; Harsch, M.; Jimenez, S. Hydroxyproline content determines the denaturation temperature of chick tendon collagen. Arch. Biochem. Biophys. 1973, 158, 478-484. [CrossRef]

44. Jenkins, C.L.; Bretscher, L.E.; Guzei, I.A.; Raines, R.T. Effect of 3-hydroxyproline residues on collagen stability. J. Am. Chem. Soc. 2003, 125, 6422-6427. [CrossRef] [PubMed]

45. Yamada, S.; Yamamoto, K.; Ikeda, T.; Yanagiguchi, K.; Hayashi, Y. Potency of fish collagen as a scaffold for regenerative medicine. BioMed Res. Int. 2014, 2014, 302932. [CrossRef] [PubMed]

46. Deyl, Z.; Mikšık, I.; Eckhardt, A. Preparative procedures and purity assessment of collagen proteins. J. Chromatogr. B 2003, 790, 245-275. [CrossRef]

47. Skierka, E.; Sadowska, M. The influence of different acids and pepsin on the extractability of collagen from the skin of baltic cod (Gadus morhua). Food Chem. 2007, 105, 1302-1306. [CrossRef]

48. Nagai, T.; Suzuki, N. Isolation of collagen from fish waste material—Skin, bone and fins. Food Chem. 2000, 68, 277-281. [CrossRef]

49. Wang, L.; An, X.; Xin, Z.; Zhao, L.; Hu, Q. Isolation and characterization of collagen from the skin of deep-sea redfish (Sebastes mentella). J. Food Sci. 2007, 72, E450-E455. [CrossRef] [PubMed]

50. Singh, P.; Benjakul, S.; Maqsood, S.; Kishimura, H. Isolation and characterisation of collagen extracted from the skin of striped catfish (Pangasianodon hypophthalmus). Food Chem. 2011, 124, 97-105. [CrossRef]

51. Mahboob, S. Isolation and characterization of collagen from fish waste material-skin, scales and fins of catla catla and cirrhinus mrigala. J. Food Sci. Technol. 2015, 52, 4296-4305. [CrossRef] [PubMed]

52. Muralidharan, N.; Shakila, R.J.; Sukumar, D.; Jeyasekaran, G. Skin, bone and muscle collagen extraction from the trash fish, leather jacket (Odonus niger) and their characterization. J. Food Sci. Technol. 2013, 50, 1106-1113. [CrossRef] [PubMed]

53. Guzzi Plepis, A.M.D.; Goissis, G.; Das-Gupta, D.K. Dielectric and pyroelectric characterization of anionic and native collagen. Polym. Eng. Sci. 1996, 36, 2932-2938. [CrossRef]

54. Kittiphattanabawon, P.; Benjakul, S.; Visessanguan, W.; Shahidi, F. Isolation and characterization of collagen from the cartilages of brownbanded bamboo shark (Chiloscyllium punctatum) and blacktip shark (Carcharhinus limbatus). LWT-Food Sci. Technol. 2010, 43, 792-800. [CrossRef]

55. Liang, Q.; Wang, L.; Sun, W.; Wang, Z.; Xu, J.; Ma, H. Isolation and characterization of collagen from the cartilage of amur sturgeon (Acipenser schrenckii). Process Biochem. 2014, 49, 318-323. [CrossRef]

56. Skopinska-Wisniewska, J.; Olszewski, K.; Bajek, A.; Rynkiewicz, A.; Sionkowska, A. Dialysis as a method of obtaining neutral collagen gels. Mater. Sci. Eng. C 2014, 40, 65-70. [CrossRef] [PubMed]

57. Muyonga, J.; Cole, C.; Duodu, K. Characterisation of acid soluble collagen from skins of young and adult nile perch (Lates niloticus). Food Chem. 2004, 85, 81-89. [CrossRef]

58. Barros, A.A.; Aroso, I.M.; Silva, T.H.; Mano, J.o.F.; Duarte, A.R.C.; Reis, R.L. Water and carbon dioxide: Green solvents for the extraction of collagen/gelatin from marine sponges. ACS Sustain. Chem. Eng. 2015, 3, 254-260. [CrossRef]

59. Lee, J.K.; Kang, S.I.; Kim, Y.J.; Kim, M.J.; Heu, M.S.; Choi, B.D.; Kim, J.-S. Comparison of collagen characteristics of sea-and freshwater-rainbow trout skin. Food Sci. Biotechnol. 2016, 25, 131-136. [CrossRef]

60. Lai, G.; Li, Y.; Li, G. Effect of concentration and temperature on the rheological behavior of collagen solution. Int. J. Biol. Macromol. 2008, 42, 285-291. [CrossRef] [PubMed]

61. Kelly, S.M.; Jess, T.J.; Price, N.C. How to study proteins by circular dichroism. Biochim. Biophys. Acta 2005, 1751, 119-139. [CrossRef] [PubMed]

62. Greenfield, N.J. Using circular dichroism spectra to estimate protein secondary structure. Nat. Protoc. 2006, 1, 2876. [CrossRef] [PubMed]

63. Li, Y.; Li, Y.; Du, Z.; Li, G. Comparison of dynamic denaturation temperature of collagen with its static denaturation temperature and the configuration characteristics in collagen denaturation processes. Thermochim. Acta 2008, 469, 71-76. [CrossRef]

64. Bigi, A.; Burghammer, M.; Falconi, R.; Koch, M.H.; Panzavolta, S.; Riekel, C. Twisted plywood pattern of collagen fibrils in teleost scales: An X-ray diffraction investigation. J. Struct. Biol. 2001, 136, 137-143. [CrossRef] [PubMed]

65. Faller, C.; Bracher, M.; Dami, N.; Roguet, R. Predictive ability of reconstructed human epidermis equivalents for the assessment of skin irritation of cosmetics. Toxicol. In Vitro 2002, 16, 557-572. [CrossRef] 
66. Robinson, M.K.; Cohen, C.; de Fraissinette, A.D.B.; Ponec, M.; Whittle, E.; Fentem, J.H. Non-animal testing strategies for assessment of the skin corrosion and skin irritation potential of ingredients and finished products. Food Chem. Toxicol. 2002, 40, 573-592. [CrossRef]

67. OECD. Test No. 439: In Vitro Skin Irritation-Reconstructed Human Epidermis Test Method; OECD Publishing: Paris, France, 2013.

68. Naik, S.M.; Cannon, G.; Burbach, G.J.; Singh, S.R.; Swerlick, R.A.; Ansel, J.C.; Caughman, S.W.; Wilcox, J.N. Human keratinocytes constitutively express interleukin-18 and secrete biologically active interleukin-18 after treatment with pro-inflammatory mediators and dinitrochlorobenzene. J. Investig. Dermatol. 1999, 113, 766-772. [CrossRef] [PubMed]

69. Cho, D.H.; Park, H.J. Il-18 and cutaneous inflammatory diseases. Int. J. Mol. Sci. 2015, 16, 29357-29369.

70. Scheller, J.; Chalaris, A.; Schmidt-Arras, D.; Rose-John, S. The pro-and anti-inflammatory properties of the cytokine interleukin-6. Biochim. Biophys. Acta 2011, 1813, 878-888. [CrossRef] [PubMed]

2017 by the authors. Licensee MDPI, Basel, Switzerland. This article is an open access article distributed under the terms and conditions of the Creative Commons Attribution (CC BY) license (http://creativecommons.org/licenses/by/4.0/). 